Article

\title{
Comprehensive Characterization of Napier Grass as a Feedstock for Thermochemical Conversion
}

\author{
Isah Y. Mohammed ${ }^{1}$, Yousif A. Abakr ${ }^{1, *}$, Feroz K. Kazi $^{2}$, Suzana Yusup ${ }^{3}$, Ibraheem Alshareef ${ }^{4}$ \\ and Soh A. Chin ${ }^{4}$
}

1 Energy, Fuel and Power Technology Research Division, School of Engineering, the University of Nottingham Malaysia Campus, Jalan Broga, Semenyih 43500, Selangor Darul Eshan, Malaysia; E-Mail: kebx3iye@nottingham.edu.my

2 Department of Chemical Engineering and Applied Chemistry, Aston University, Aston Triangle, Birmingham B4 7ET, UK; E-Mail: f.kabir@aston.ac.uk

3 Department of Chemical Engineering, Universiti Teknology Petronas (UTP), Bandar Seri Iskandar, Tronoh 31750, Malaysia; E-Mail: drsuzana_yusuf@petronas.com.my

4 Crops for the Future (CFF), the University of Nottingham Malaysia Campus, Jalan Broga, Semenyih 43500, Selangor Darul Eshan, Malaysia;

E-Mails: ibraheem.alshareef@cffresearch.org (I.A.); soh.aikchin@cffresearch.org (S.A.C.)

* Author to whom correspondence should be addressed; E-Mail: yousif.abakr@nottingham.edu.my; Tel.: +60-132-321-232.

Academic Editor: Thomas E. Amidon

Received: 18 March 2015 / Accepted: 16 April 2015 / Published: 24 April 2015

\begin{abstract}
Study on Napier grass leaf (NGL), stem (NGS) and leaf and stem (NGT) was carried out. Proximate, ultimate and structural analyses were evaluated. Functional groups and crystalline components in the biomass were examined. Pyrolysis study was conducted in a thermogravimetric analyzer under nitrogen atmosphere of $20 \mathrm{~mL} / \mathrm{min}$ at constant heating rate of $10 \mathrm{~K} / \mathrm{min}$. The results reveal that Napier grass biomass has high volatile matter, higher heating value, high carbon content and lower ash, nitrogen and sulfur contents. Structural analysis shows that the biomass has considerable cellulose and lignin contents which are good candidates for good quality bio-oil production. From the pyrolysis study, degradation of extractives, hemicellulose, cellulose and lignin occurred at temperature around 478, 543, 600 and above $600 \mathrm{~K}$, respectively. Kinetics of the process was evaluated using reaction order model. New equations that described the process were developed using the kinetic parameters and data compared with experimental data. The results of the models fit well to
\end{abstract}


the experimental data. The proposed models may be a reliable means for describing thermal decomposition of lignocellulosic biomass under nitrogen atmosphere at constant heating rate.

Keywords: Napier grass; characterization; proximate and ultimate analysis; XRD; FTIR; TGA; DTG

\section{Introduction}

Development of alternative renewable energy continues to grow in recent times due to the fear of energy insecurity in the near future and environmental cum sociopolitical issues associated with the use of fossil fuels. Application of lignocellulosic biomass (non-food materials) such as forest residues, agro-wastes, energy grasses, aquatic plants and algae, etc. for bioenergy production seem promising as they are evenly distributed across the globe and have also eliminated initial public perception of food insecurity associated with first generation biofuels which were produced from food materials [1-3]. In addition, these materials have low levels of sulfur, nitrogen and ash content which make them relatively environmentally friendly. Napier grass (Pennisetum purpureum) is an herbaceous plant with high potential for use as a feedstock for biofuel processing. It has a high biomass yield compared to other energy grasses such as miscanthus, switchgrass, etc, typically in the range of 25-35 oven dry tons per hectare annually, which corresponds to 100 barrels of oil energy equivalent per hectare. Cultivation of Napier grass follows conventional farming practices. It outcompetes weeds, needs very little or no supplementary nutrients and therefore requires lower establishment costs. It can be harvested up to four times within a year with a ratio of energy output to energy input of around 25:1, hence making it one of the best potential energy crops for development of efficient and economic bioenergy systems [4]. Furthermore, our recent trials in the field have proved that Napier grass can be intercropped with oil palm. The study was conducted under $70 \%$ and $50 \%$ shade levels with a full sunlight treatment as control. The plant showed more potential for higher dry weights in shaded conditions due to its elongated stem which contained more biomass than the higher leaf biomass produced in unshaded conditions. This suggests that shaded Napier grass produces longer and thicker stems in an attempt to reach better quality light. Intercropping Napier grass with oil palm will offer higher biomass yield, minimize the unused spaces in the oil palm plantation (estimated at $26.63 \%$ of the total space) and bring added economic value to the oil palm industries.

Compared to other herbaceous biomass resources few studies on the characteristics of Napier grass biomass and its utilization for the development of biomaterials and biofuels have been carried out. Recently, Reddy et al. [5,6] have studied the thermal properties of Napier grass fiber, and its chemical and structural characterization, respectively. Effects of alkaline pretreatment on the thermal stability and mechanical properties were investigated. The findings revealed that alkali-pretreated Napier grass fiber can be used as reinforcement in green composites. Strezov et al. [7] and Lee et al. [8] also conducted studies on the thermochemical conversion of Napier grass to pyrolysis oil. The results of their separate investigations showed that the bio-oil was made up of highly oxygenated compounds which was attributed to the nature of the composition of the grass. In order to develop effective and efficient conversion of Napier grass into biofuel and chemicals via pyrolysis, there is need to further understand 
its properties so as to be able to predict product compositions, yields, selectivity and co-products formed during conversion. The objective of this paper was to carry out a comprehensive characterization of the different parts of Napier grass for sustainable biofuel production.

\section{Experiment}

Fresh Napier grass stem (NGS), leaf (NGL) and stem and leaf (NGT) chopped 6 to $8 \mathrm{~cm}$ were collected from the Crops for the Future (CFF) Field Research Centre and transported in plastic bags to the research building of the University of Nottingham Malaysia campus. The materials were oven dried at $105^{\circ} \mathrm{C}$ for moisture content determination according to the BS EN 14774-1 standard [9]. The dried materials were then shredded in a Retsch ${ }^{\circledR}$ rotor beater mill to particle sizes between $0.2 \mathrm{~mm}$ and $2 \mathrm{~mm}$ and stored in air tight plastic bags for further studies. Volatile matter and ash content on dry basis were determined according BS EN 15148 [10] and BS EN 14775 [11], respectively. Fixed carbon was computed by subtracting the percentage compositions of ash and volatile matter from the bone dry sample mass. Higher heating value (HHV) was determined using a Parr 6100 oxygen bomb calorimeter following BS EN 14918 [12]. The ash inorganic composition was determined using energy dispersive $\mathrm{x}$-ray (EDX). Elemental compositions were determined using a LECO Corporation, USA CHNS analyzer (LECO Corporation, St Joseph, MI, USA). The structural analysis of the biomass was performed according to the procedure outlined in NREL/TP-510-42618 [13]. X-ray diffraction (XRD) was carried out to examine the crystalline systems present in each sample using PANalytical XpertPro (DSKH Technology Sdn Bhd, Selangor, Malaysia) (CuK $\alpha$ radiation, $\lambda=0.1541 \mathrm{~nm}$ ) between $2 \Theta$ angle of $10^{\circ}-60^{\circ}$ at $25 \mathrm{~mA}, 45 \mathrm{kV}$, step size of $0.025^{\circ}$ and $1.0 \mathrm{~s}$ scan rate. Crystallinity index (CrI) was calculated using peak height method according to Equation (1) below [14]:

$$
\operatorname{CrI}(\%)=\left[\frac{I_{200}-I_{a m}}{I_{200}}\right] \times 100
$$

where $I_{200}$ and $I_{a m}$ is the intensity of crystalline and amorphous portion of the biomass respectively. The nature of chemical bonds and functional groups was evaluated by Fourier transform infrared spectroscopy (FTIR) on a PerkinElmer Spectrometer Spectrum RX1 instrument (Perkin Elmer Sdn Bhd, Selangor, Malaysia) using the potassium bromide $(\mathrm{KBr})$ method. The translucent $\mathrm{KBr}$ discs (13 mm diameter) were made from homogenized $2 \mathrm{mg}$ samples in $100 \mathrm{mg} \mathrm{KBr}$ using a CARVER press at 5.5 tons for $5 \mathrm{~min}$. Spectra were recorded with the Spectrum V5.3.1 software within the wavenumber range of $400-4000 \mathrm{~cm}^{-1}$ at 32 scans and $4 \mathrm{~cm}^{-1}$ resolution. Pyrolysis characteristics of the samples were studied in a PerkinElmer Simultaneous Thermal Analyzer (STA) 6000 thermogravimetric analyzer (TGA) (Perkin Elmer Sdn Bhd, Selangor, Malaysia) in a nitrogen atmosphere, flow rate $20 \mathrm{~mL} / \mathrm{min}$ at temperature between $300 \mathrm{~K}$ and $1100 \mathrm{~K}$ and heating rate of $10 \mathrm{~K} / \mathrm{min}$. About $10.0 \mathrm{mg}$ of sample (with a particle size of $0.2 \mathrm{~mm}$ ) was used.

\section{Results and Discussion}

Table 1 gives the characteristics of different part of the Napier grass biomass. Moisture content at harvest varied across different section of the plant. Napier grass stem (NGS) has the highest moisture of 75.27 wt. \%, followed by the Napier grass total, NGT (stem and leaf) with 74.22 wt. \% and the least 
from leaf (NGL) having 62.25 wt. \%. High volatile matter of 85.17 wt. \%, 81.51 wt. \% and 79.06 wt. \% was recorded in the NGT, NGS and NGL, respectively. Ultimate analysis on a dry basis revealed that NGS has higher carbon (48.61 wt. \%) and lower oxygen (44.07 wt. \%) contents relative to NGT with 45.10 wt. \% carbon, 47.17 wt. \% oxygen and NGL (44.17 wt. \% carbon, 49.04 wt. \% oxygen).

Table 1. Proximate, ultimate, structural and ash characteristics of Napier grass (NGS, NGL and NGT).

\begin{tabular}{|c|c|c|c|}
\hline \multirow{2}{*}{ Property } & \multicolumn{3}{|c|}{ Biomass } \\
\hline & NGS & NGL & NGT \\
\hline \multicolumn{4}{|c|}{ Proximate analysis (wt. \%) } \\
\hline Moisture content $^{\mathrm{a}}$ & $75.27 \pm 0.21$ & $62.25 \pm 0.14$ & $74.22 \pm 0.17$ \\
\hline Volatile matter ${ }^{\mathrm{b}}$ & $81.51 \pm 0.30$ & $79.06 \pm 0.26$ & $85.17 \pm 0.21$ \\
\hline Ash content ${ }^{b}$ & $1.75 \pm 0.01$ & $4.00 \pm 0.03$ & $6.34 \pm 0.01$ \\
\hline Fixed carbon ${ }^{c}$ & $16.74 \pm 0.09$ & $16.94 \pm 0.04$ & $8.49 \pm 0.02$ \\
\hline HHV (MJ/kg) & $18.11 \pm 0.10$ & $16.21 \pm 0.10$ & $16.58 \pm 0.10$ \\
\hline \multicolumn{4}{|c|}{ Ultimate analysis (wt. \%) ${ }^{b}$} \\
\hline Carbon (C) & $48.61 \pm 0.80$ & $44.17 \pm 0.73$ & $45.10 \pm 0.70$ \\
\hline Hydrogen $(\mathrm{H})$ & $6.01 \pm 0.14$ & $5.51 \pm 0.14$ & $5.93 \pm 0.15$ \\
\hline Nitrogen $(\mathrm{N})$ & $0.99 \pm 0.03$ & $1.01 \pm 0.03$ & $1.45 \pm 0.04$ \\
\hline Sulfur (S) & $0.32 \pm 0.01$ & $0.27 \pm 0.01$ & $0.35 \pm 0.01$ \\
\hline Oxygen $(\mathrm{O})^{\mathrm{c}}$ & $44.07 \pm 0.66$ & $49.04 \pm 0.74$ & $47.17 \pm 0.71$ \\
\hline $\mathrm{O} / \mathrm{C}$ (atomic ratio) & 0.91 & 1.11 & 1.05 \\
\hline $\mathrm{H} / \mathrm{C}$ (atomic ratio) & 0.124 & 0.125 & 0.131 \\
\hline \multicolumn{4}{|c|}{ Structural composition (wt. \%) } \\
\hline Cellulose & $38.75 \pm 2.30$ & $29.36 \pm 2.01$ & $34.21 \pm 2.17$ \\
\hline Hemicellulose & $19.76 \pm 1.68$ & $15.96 \pm 1.55$ & $20.44 \pm 1.70$ \\
\hline Lignin & $26.99 \pm 1.29$ & $30.09 \pm 1.30$ & $24.34 \pm 1.34$ \\
\hline Extractives & $12.07 \pm 0.32$ & $5.57 \pm 0.30$ & $9.26 \pm 0.27$ \\
\hline \multicolumn{4}{|c|}{ EDX Analysis of ash (wt. \%) } \\
\hline Sodium (Na) & $0.27 \pm 0.006$ & $0.21 \pm 0.004$ & $0.25 \pm 0.005$ \\
\hline Magnesium (Mg) & $2.34 \pm 0.075$ & $2.17 \pm 0.070$ & $1.89 \pm 0.049$ \\
\hline Aluminum (Al) & $0.93 \pm 0.032$ & $1.67 \pm 0.057$ & $1.66 \pm 0.057$ \\
\hline Silicon (Si) & $7.44 \pm 0.248$ & $24.98 \pm 0.833$ & $7.78 \pm 0.265$ \\
\hline Phosphorus (P) & $2.31 \pm 0.064$ & $3.55 \pm 0.107$ & $2.25 \pm 0.068$ \\
\hline Sulfur (S) & $1.47 \pm 0.047$ & $1.75 \pm 0.060$ & $3.37 \pm 0.104$ \\
\hline Chlorine $(\mathrm{Cl})$ & $16.13 \pm 0.471$ & $12.44 \pm 0.400$ & $18.95 \pm 0.653$ \\
\hline Potassium (K) & $64.77 \pm 2.228$ & $49.88 \pm 1.716$ & $59.85 \pm 2.061$ \\
\hline Calcium $(\mathrm{Ca})$ & $4.34 \pm 0.129$ & $3.34 \pm 0.100$ & $4.01 \pm 0.129$ \\
\hline
\end{tabular}

Notes: ${ }^{a}$ As received at harvest; ${ }^{b}$ dry basis; ${ }^{c}$ by difference; (NGS) Napier grass stem; (NGL) Napier grass leaf and (NGT) Napier grass stem and leaf.

NGS produced a higher heating value (HHV) of $18.11 \mathrm{MJ} / \mathrm{kg}$ compared to NGT $(16.58 \mathrm{MJ} / \mathrm{kg})$ and NGL $(16.21 \mathrm{MJ} / \mathrm{kg})$. The higher energy content in the NGS may be attributed to its lower ash content, high carbon content and lower oxygen level. EDX analysis of biomass ash showed that ash from all parts of the Napier grass contains similar metallic and non-metallic elements in different proportions in the following order $\mathrm{K}>\mathrm{Ca}>\mathrm{Mg}>\mathrm{Al}>\mathrm{Na}$ and $\mathrm{Cl}>\mathrm{Si}>\mathrm{P}>\mathrm{S}$, respectively. This composition follows general 
trend of a typical biomass ash [7,15-17]. Result of structural analysis revealed that NGS has 38.75 wt. \% cellulose, 19.76 wt. \% hemicellulose and 26.99 wt. \% lignin while 34.21 wt. \%, 20.44 wt. \%, 24.34 wt. \% and 29.36 wt. \%, 15.96 wt. \%, 30.09 wt. \% of cellulose, hemicellulose, lignin were recorded in NGT and NGL respectively. This structural characteristica are similar to those o obtained by Reddy et al. [5], and Lee et al. [8] and those of other warm season grasses such as switchgrass, Miscanthus, etc. [18,19].

The diffraction pattern (Figure 1) from the XRD study shows similar patterns for all the biomass samples with peaks at a $2 \Theta$ value of $22.16^{\circ}$ (main peak), $15.81^{\circ}$ and $35.10^{\circ}$ (broad peaks) which reflect the crystalline system in the samples. These represent the crystallographic planes 200, 110 and 004 , respectively, according to the native cellulose structure [20-23]. These characteristic peaks in the diffractogram are comparable to the Napier grass peaks identified by Reddy et al. [6]. The remaining components, mainly hemicellulose, lignin and extractives in the material are approximated to belong to the amorphous phase since no larger crystals are formed by these components [20,24]. The value of crystallinity index obtained using Equation (1) above was 79.15\%, 76.14 and 75.41 for NGS, NGT and NGL correspondingly. This result shows good agreement with the structural analysis result.

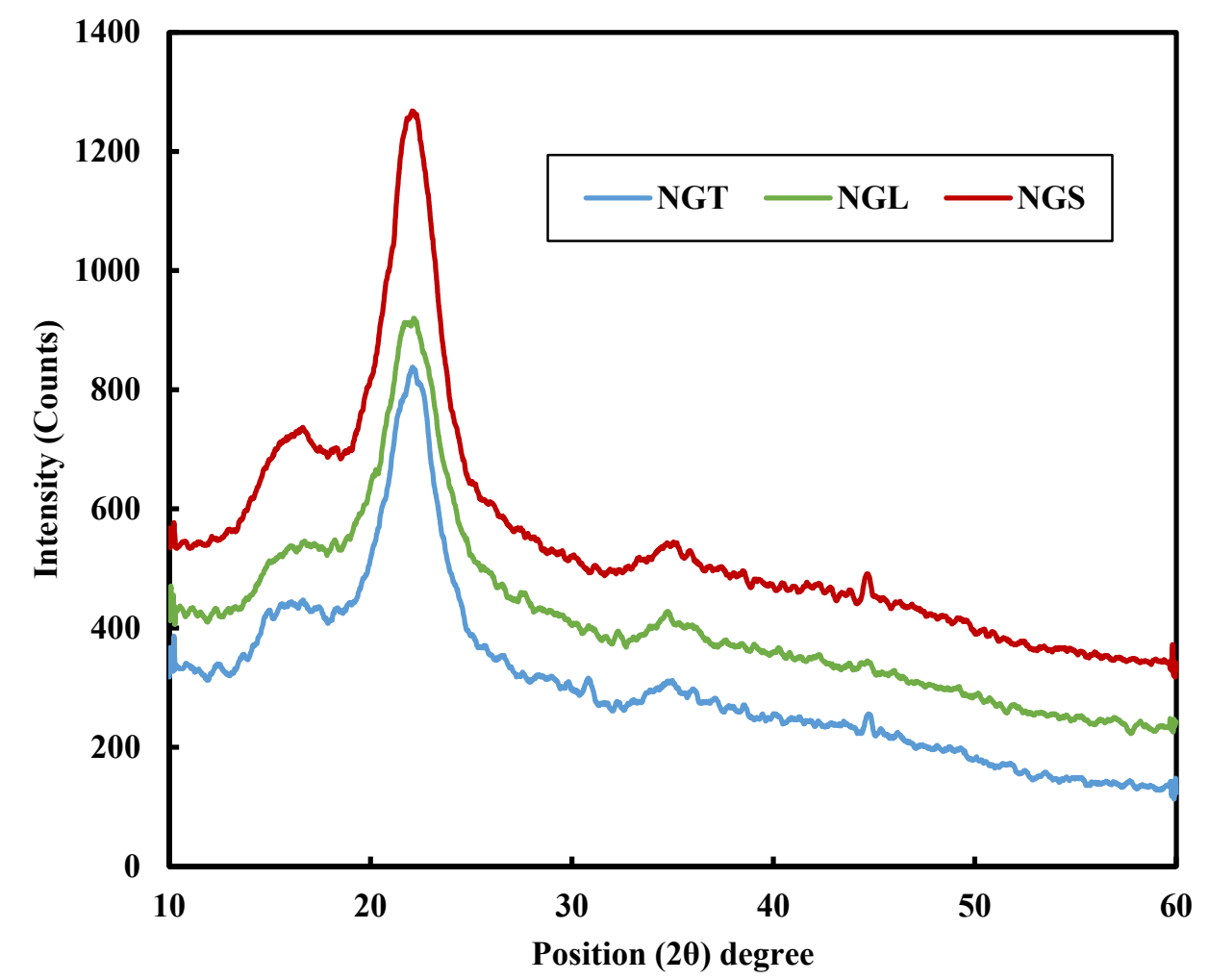

Figure 1. X-ray diffractogram of Napier grass (NGT, NGS and NGL).

Table 2 below lists typical FTIR wavenumber bands for the biomass material. The averaged FTIR spectra (Figure 2) show similar characteristic peaks for all the biomass samples, with a region of high frequency between $4000 \mathrm{~cm}^{-1}$ and $2300 \mathrm{~cm}^{-1}$ and region of low frequency between $1626 \mathrm{~cm}^{-1}$ and $400 \mathrm{~cm}^{-1}$ which indicates the possible presence of different alkyl, aromatic, alcohol, ester and carbonyl functional groups originating from the extractive, hemicellulose, cellulose and lignin components of all the biomass. In the high frequency region, peaks in the samples between $3700 \mathrm{~cm}^{-1}$ and $3421 \mathrm{~cm}^{-1}$ can be attributed to different hydroxyl group (alcohol/phenol) stretching vibrations [25-28]. The band at $2937 \mathrm{~cm}^{-1}$ 
could be a result of aliphatic saturated $\mathrm{C}-\mathrm{H}$ stretching vibrations (asymmetric and symmetric methyl and methylene stretching groups) from extractives and lignin components of the biomass since fatty acid methyl esters and phenolic acid methyl esters, have methyl and methylene groups [29-32]. In the fingerprint region, the band at $1600 \mathrm{~cm}^{-1}$ may be due to the ring-conjugated $\mathrm{C}=\mathrm{C}$ bonds of lignin while the band observed at $1200 \mathrm{~cm}^{-1}$ may be an indication of $\mathrm{O}-\mathrm{H}$ bending in the cellulose and hemicellulose components of the biomass [5,25,26,28,33-36]. The frequency at $1,050 \mathrm{~cm}^{-1}$ may be ascribed to $\mathrm{C}-\mathrm{O}$, and $\mathrm{C}=\mathrm{C}$, and $\mathrm{C}-\mathrm{C}-\mathrm{O}$ stretching in cellulose, hemicelluloses and lignin $[25,28,34,36]$ while the bands between 800 and $600 \mathrm{~cm}^{-1}$ may be attributed to aromatic $\mathrm{C}-\mathrm{H}$ bending vibrations from the lignin in the samples $[5,35,36]$.

Table 2. FTIR wavenumber bands in biomass material.

\begin{tabular}{ccc}
\hline Wavenumber $\left(\mathbf{c m}^{-\mathbf{1}}\right)$ & Functional Group & Reference \\
\hline 3700,3421 & O-H Stretching vibration & {$[25-28]$} \\
2937 & Alkyl C-H stretching & {$[29-32]$} \\
1600 & Aromatic C=C Bending & {$[26,35,36]$} \\
1200 & O-H bending in cellulose and hemicellulose & {$[5,25,28,34,36]$} \\
1050 & C-O, C=C and C-C-O stretching & {$[5,24,28,34,36]$} \\
$860-680$ & Aromatic C-H bending & {$[5,35,36]$} \\
\hline
\end{tabular}

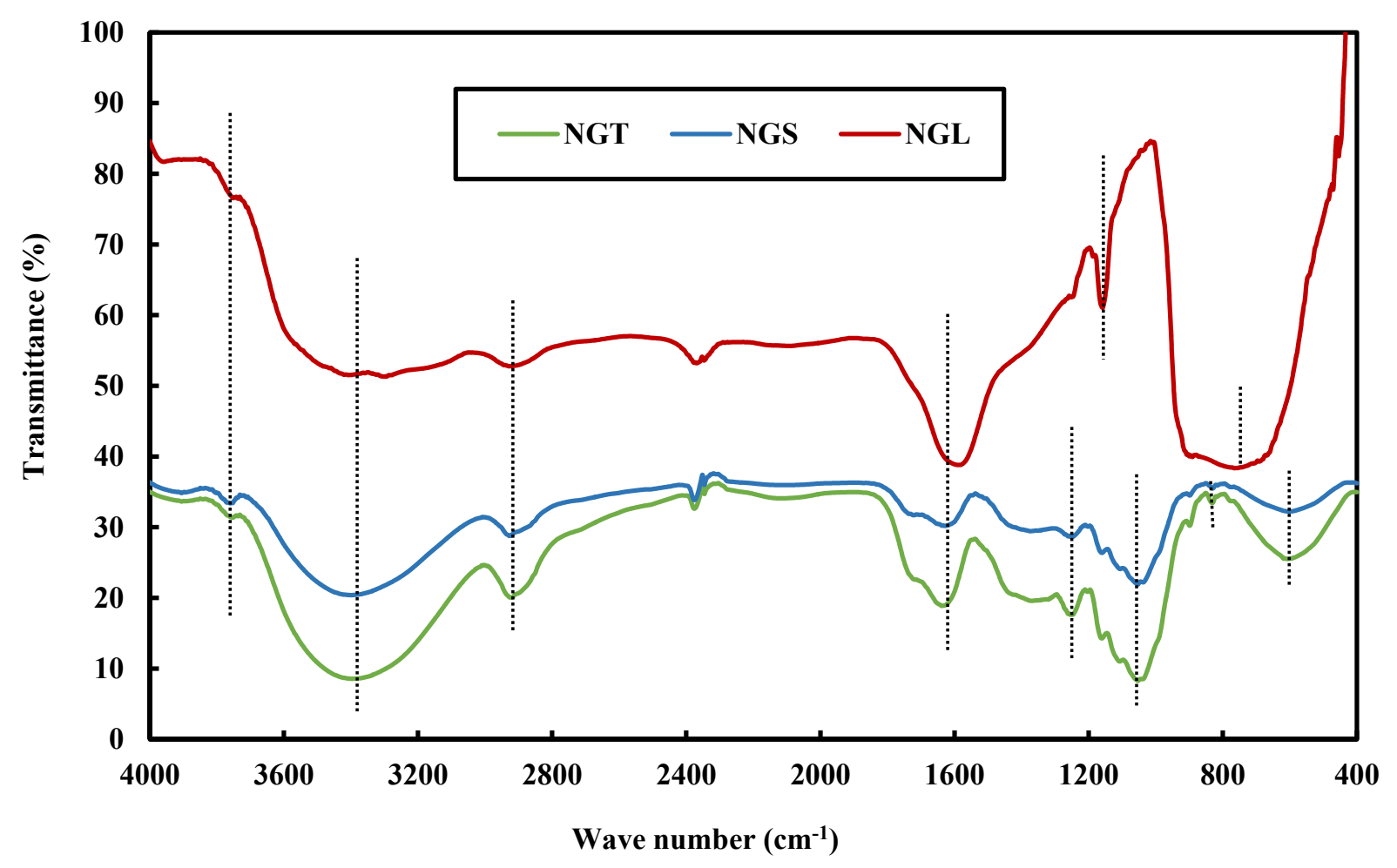

Figure 2. Averaged FTIR spectra (auto-smoothed and auto-baseline corrected) of Napier grass samples (NGT, NGS and NGL).

Thermogravimetric analysis revealed thermal decomposition of various structural components of NGS, NGT and NGL (Figure 3). Point (a) at $478 \mathrm{~K}$ is attributed to decomposition of extractives while (b) and (c) correspond to decomposition of hemicellulose at temperatures $543 \mathrm{~K}$ and cellulose at $600 \mathrm{~K}$, 
respectively. Beyond $600 \mathrm{~K}$, point (d), indicates the decomposition of lignin. Considering decomposition intensity of the main peaks (cellulose), reaction intensities of 5.3, 6.0 and $6.6 \mathrm{wt}$ \%/K were recorded for NGS, NGT and NGL in that order. The lower value for NGS may be attributed to w high amount of alkali metals, particularly potassium, in the biomass (see Table 1) since high levels of alkali metals tends to reduce the cellulose decomposition rate during pyrolysis [36-39]. A noticeable peak was observed in the lignin decomposition region of NGT at $730 \mathrm{~K}$ and NGL at $880 \mathrm{~K}$ while none was observed in NGS. Consequently, it can be deduced that the lignin content of NGS has similar decomposition pathways while the change observed in the NGT and NGL may be attributed to different oxygen functional groups present in the lignin component of the respective biomass sanmples. The decomposition temperature values of different parts of the Napier grass in this study are in good agreement with literature values of 373-523 K, 523-623 K, 623-773 K and above $773 \mathrm{~K}$ for extractives, hemicellulose, cellulose and lignin, respectively $[6,36,39]$.

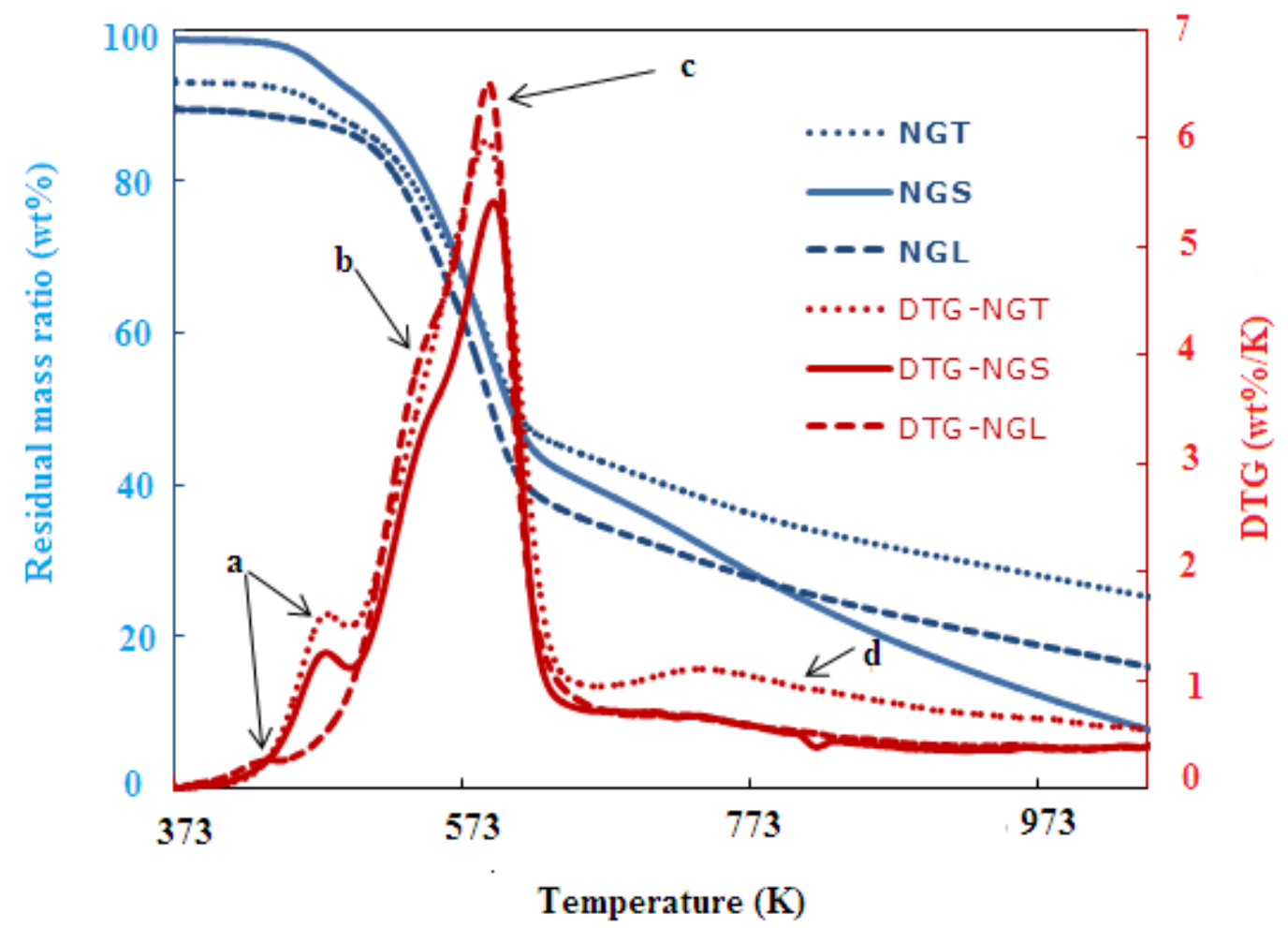

Figure 3. Residual mass ratio and DTG of Napier grass on dry basis. (NGT) Napier grass stem and leaf, (NGS) Napier grass stem, (NGL) Napier grass leaf. (a) Extractives; (b) Hemicellulose; (c) Cellulose; and (d) lignin decompositions respectively. Condition: nitrogen atmosphere $(20 \mathrm{~mL} / \mathrm{min})$, heating rate $(10 \mathrm{~K} / \mathrm{min})$.

Biomass decomposition can be represented by the Equation (2) below:

$$
B_{(s)} \stackrel{k}{\longrightarrow} V_{(g)}+R s_{(s)}
$$

where $B$ : solid biomass; $V$ : volatiles and $R s$ : residual solid. $k$ : decomposition rate constant.

From solid state chemistry, the rate of reaction can be written as [40]:

$$
\frac{d x_{b}}{d t}=k(T) f\left(x_{b}\right)
$$


The rate constant $k$ is a function of temperature and generally represented by the Arrhenius equation and $f\left(x_{b}\right)$ is expressed in form of reaction order model. Equation (3) then becomes:

$$
\frac{d x_{b}}{d t}=\left(1-x_{b}\right)^{n} \times A e^{-\frac{E}{R T}}
$$

For a non-isothermal process at constant heating rate $(\beta)$, Equation (4) can be transformed as given in Equation (5):

$$
\frac{d x_{b}}{d t}=\frac{d x_{b}}{d T} \times \frac{d T}{d t}=(\beta) \frac{d x_{b}}{d T}=\left(1-x_{b}\right)^{n} \times A e^{-\frac{E}{R T}}
$$

Taking the natural logarithm of Equation (5) and rearranging, we obtain Equation (6). A plot of right hand side versus $1 / T$ will give a straight line for a particular reaction order. The kinetic parameters; frequency factor, $A\left(\mathrm{~min}^{-1}\right)$ and activation energy, $E(\mathrm{~kJ} / \mathrm{mol})$ can be obtained from the intercept and slope of the graph. $R$ is the general gas constant $(8.314 \mathrm{~J} / \mathrm{mol} \cdot \mathrm{K})$ :

$$
\begin{gathered}
\ln \left[\frac{(\beta) \frac{d x_{b}}{d T}}{\left(1-x_{b}\right)^{n}}\right]=\ln A-\frac{E}{R} \times\left[\frac{1}{T}\right] \\
x_{b}=\text { conversion ratio }=\frac{m_{o}-m_{t}}{m_{o}-m_{\infty}}=\frac{1-\left(\frac{m_{t}}{m_{o}}\right)}{1-\left(\frac{m_{\infty}}{m_{o}}\right)}=\frac{1-\alpha_{t}}{1-\alpha_{\infty}}=\frac{1-\alpha_{t}}{K_{\infty}} ; K_{\infty}=1-\alpha_{\infty}
\end{gathered}
$$

where the terms $m_{o}, m_{t}$, and $m_{\infty}$ are the initial sample mass, mass remaining at any time $(t)$ and residual mass at the end of pyrolysis, respectively.

From Equation (7), we need to develop the limit for $d x b / d T$ and relate it to the experimental data:

$$
d x_{b}=d\left[\frac{1-\alpha_{t}}{K_{\infty}}\right]=\frac{1}{\mathrm{~K}_{\infty}} d\left[1-\alpha_{t}\right]=\frac{1}{\mathrm{~K}_{\infty}}\left[0-d \alpha_{t}\right]=-\frac{1}{\mathrm{~K}_{\infty}} d \alpha_{t}
$$

From the above $\alpha_{t}=\frac{m_{t}}{m_{o}} \Rightarrow d \alpha_{t}=\frac{1}{m_{o}} d m_{t}$ and Equation (8) now becomes:

$$
\frac{d x_{b}}{d T}=-\frac{1}{\mathrm{~K}_{\infty}} \times \frac{1}{m_{o}} \frac{d m_{t}}{d T}
$$

But $D T G=-\frac{d w}{d T}(\% / K)$ and $w(\%)=\frac{m_{t}}{m_{o}} \times 100$

$$
\Rightarrow \frac{d m_{t}}{d T}=\frac{m_{o}}{100} \times \frac{d w}{d T}(\% / K)
$$

Substituting Equation (10) in (9), we have:

$$
\frac{d x_{b}}{d T}=-\frac{1}{\mathrm{~K}_{\infty}} \times \frac{1}{m_{o}} \times\left[\frac{m_{o}}{100} \frac{d w}{d T}\right]=-\frac{1}{100 \mathrm{~K}_{\infty}}\left[\frac{d w}{d T}\right]
$$


The experimental data were fitted to the straight line model presented in the Equation (6) above for different components in the biomass as identified in the DTG curves in Figure 3 above. Summarized kinetic parameters such as activation energy, frequency factor and reaction order are given in Table 3. The lignin decomposition NGS and NGL biomass samples followed a reaction order of 1.8 while a 2.3 reaction order was recorded for NGT. The activation energy was between 23.37 and $46.31 \mathrm{~kJ} / \mathrm{mol}$ which was lower than that of the remaining components. This observation may be attributed to mass and heat transfer effects. Similar lower values of activation energy of lignin decomposition have been reported in the literature [41-45]. Similarly, the cellulose and extractives decompositions of NGS and NGL biomass obeyed the same reaction order of 5, whereas NGT followed 7 and 11 reaction orders for cellulose and extractives. High activation energies of $178.62,171.25$ and $168.84 \mathrm{~kJ} / \mathrm{mol}$ were recorded for cellulose in NGT, NGS and NGL, respectively. The higher value of activation energy of cellulose may be linked to the high crystallinity index recorded in the samples which generally tends to inhibit cellulose degradation due to resistance to heat diffusion [36,37,46,47]. This observation is also in agreement with our previous study where pretreated biomass produced higher activation energy compared to the untreated sample due to increased crystallinity brought about by the pretreatment [39]. On the other hand, the reaction orders for hemicellulose varied across all the biomass samples: orders of 4.5, 3 and 5 were recorded for hemicellulose decomposition in NGT, NGS and NGL, respectively with corresponding activation energy of $81.05,82.59$ and $102.56 \mathrm{~kJ} / \mathrm{mol}$.

Table 3. Kinetic parameters of pyrolysis Napier grass (NGT, NGS and NGL) under nitrogen atmosphere $(20 \mathrm{~mL} / \mathrm{min})$ and heating rate of $10 \mathrm{~K} / \mathrm{min}$ using reaction order model.

\begin{tabular}{ccccccc}
\hline Biomass & Slope & Intercept & Order $(\boldsymbol{n})$ & R-Square Value & $\mathbf{A}\left(\mathbf{m i n}^{-\mathbf{1}}\right)$ & $\mathbf{E}_{\mathbf{A}}(\mathbf{k J} \mathbf{m o l} \mathbf{)})$ \\
\hline $\boldsymbol{N G T}$ & & & & & & \\
\hline Extractives & $-11,578.0$ & 23.217 & 11.00 & 0.9880 & $1.21 \times 10^{10}$ & 96.26 \\
Hemicellulose & $-9,748.3$ & 17.982 & 4.50 & 0.9991 & $6.45 \times 10^{7}$ & 81.05 \\
Cellulose & $-21,484.0$ & 39.912 & 7.00 & 0.9786 & $2.16 \times 10^{17}$ & 178.62 \\
Lignin & $-5,570.1$ & 8.3817 & 2.30 & 0.9961 & $4.37 \times 10^{3}$ & 46.31 \\
\hline $\boldsymbol{N G S}$ & & & & & & \\
\hline Extractives & $-9,470.8$ & 18.854 & 5.00 & 0.9813 & $1.54 \times 10^{8}$ & 78.74 \\
Hemicellulose & $-9,933.8$ & 18.416 & 3.00 & 0.9990 & $9.95 \times 10^{7}$ & 82.59 \\
Cellulose & $-20,597.0$ & 38.25 & 5.00 & 0.9573 & $4.09 \times 10^{16}$ & 171.25 \\
Lignin & $-2,811.1$ & 4.3639 & 1.80 & 0.9697 & $7.86 \times 10^{1}$ & 23.37 \\
\hline $\boldsymbol{N G L}$ & & & & & & \\
\hline Extractives & $-6,700.4$ & 12.25 & 5.00 & 0.9864 & $2.09 \times 10^{5}$ & 55.71 \\
Hemicellulose & $-12,335.0$ & 23.345 & 4.00 & 0.9993 & $1.38 \times 10^{10}$ & 102.56 \\
Cellulose & $-20,307.0$ & 38.054 & 5.00 & 0.9317 & $3.36 \times 10^{16}$ & 168.84 \\
Lignin & $-3,234.2$ & 4.9492 & 1.80 & 0.9927 & $1.41 \times 10^{2}$ & 26.89 \\
\hline
\end{tabular}

Generally, the biomass decomposition process is a multi-step reaction of its components which contribute to the overall reaction rate. From the kinetic parameters obtained above, a general equation can be developed for the whole NGT, NGS and NGL biomass decomposition process from Equation (5), as follows: 


$$
\begin{gathered}
{\left[\frac{d x_{b}}{d T}\right]_{N G T}=\frac{A}{\beta} e^{-\frac{E}{R T}}\left[\left(1-x_{b}\right)^{11}+\left(1-x_{b}\right)^{4.5}+\left(1-x_{b}\right)^{7}+\left(1-x_{b}\right)^{2.3}\right]} \\
=\frac{A}{\beta} e^{-\frac{E}{R T}}\left[\left(1-x_{b}\right)^{2 n+1}+\left(1-x_{b}\right)^{(2 n-1) / 2}+\left(1-x_{b}\right)^{n+2}+\left(1-x_{b}\right)^{(5 n-2) / 2 n}\right] \\
{\left[\frac{d x_{b}}{d T}\right]_{N G S}=\frac{A}{\beta} e^{-\frac{E}{R T}}\left[\left(1-x_{b}\right)^{5}+\left(1-x_{b}\right)^{3}+\left(1-x_{b}\right)^{5}+\left(1-x_{b}\right)^{1.8}\right]} \\
=\frac{A}{\beta} e^{-\frac{E}{R T}}\left[\left(1-x_{b}\right)^{n}+\left(1-x_{b}\right)^{n-2}+\left(1-x_{b}\right)^{n}+\left(1-x_{b}\right)^{(2 n-1) / n}\right] \\
{\left[\frac{d x_{b}}{d T}\right]_{N G L}=\frac{A}{\beta} e^{-\frac{E}{R T}}\left[\left(1-x_{b}\right)^{5}+\left(1-x_{b}\right)^{4}+\left(1-x_{b}\right)^{5}+\left(1-x_{b}\right)^{1.8}\right]} \\
=\frac{A}{\beta} e^{-\frac{E}{R T}}\left[\left(1-x_{b}\right)^{n}+\left(1-x_{b}\right)^{n-1}+\left(1-x_{b}\right)^{n}+\left(1-x_{b}\right)^{(2 n-1) / n}\right]
\end{gathered}
$$

where $n=5$ and the first, second, third and fourth term of Equations (12)-(14) represent the rate of conversion of extractives, hemicellulose, cellulose and lignin at temperatures between 373-473 K, $473-573 \mathrm{~K}, 573-673 \mathrm{~K}$ and $>673 \mathrm{~K}$, respectively. Using these models with the kinetic parameters obtained above, predicated DTG data was obtained using the relation in Equation (11). The predicated DTG was compared with the experimental DTG as shown in Figure 4 below. The result showed that the models described well the pyrolysis process of the different components of Napier grass biomass.

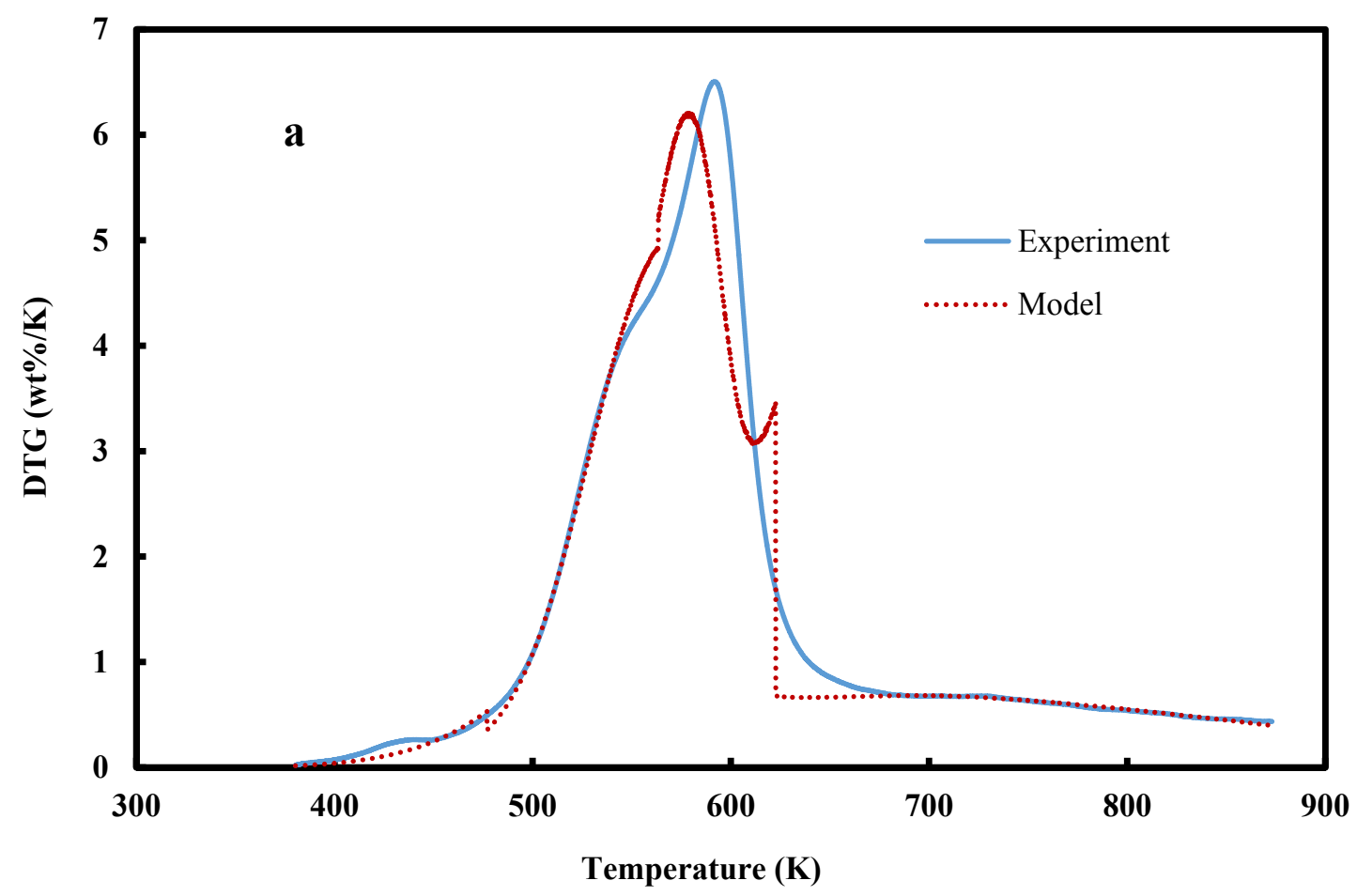

Figure 4. Cont. 

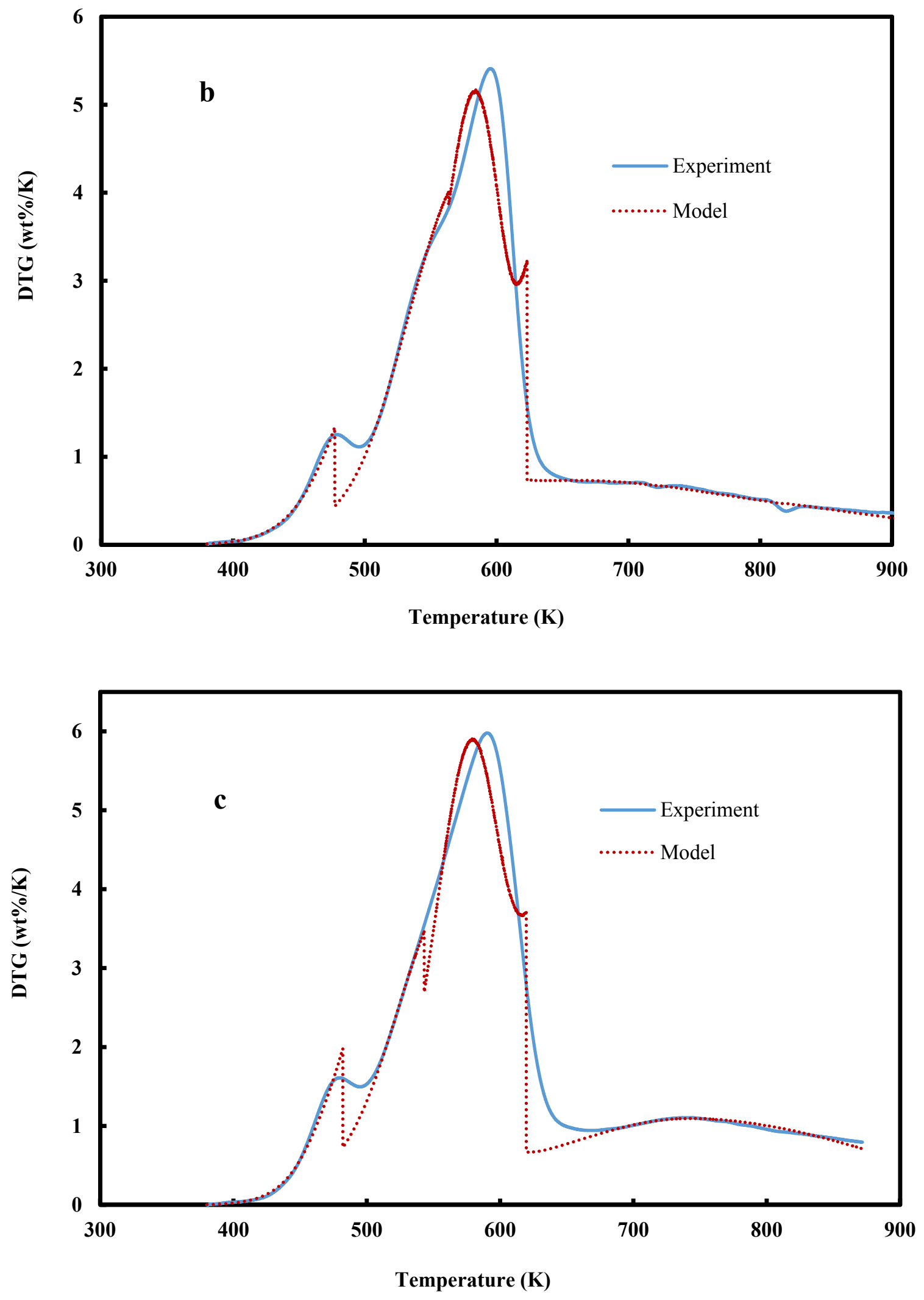

Figure 4. Comparison between Experimental and Predicted DTG curves of Napier Grass Biomass. (a) NGL; (b) NGS; (c) NGT. 


\section{Conclusions}

Napier grass leaf (NGL), stem (NGS) and leave and stem (NGT) were characterized. Proximate and ultimate analyses revealed that the materials have high volatile matter contents, higher heating value, high carbon content and lower ash, nitrogen and sulfur contents. Structural composition showed that Napier grass biomass has considerable cellulose and lignin contents which makes it a good candidate for good quality bio-oil production. However, some levels of extractives and hemicellulose were also recorded. The biomass ash consists mainly of the elements potassium, chlorine and silicon. These minerals, together with extractives and hemicellulose, may be reduced through a pretreatment step prior to the pyrolysis process. The pyrolysis characteristics from the thermogravimetric studies under nitrogen atmosphere of $20 \mathrm{~mL} / \mathrm{min}$ at constant heating rate of $10 \mathrm{~K} / \mathrm{min}$ showed that degradation of extractives, hemicellulose, cellulose and lignin occurred at temperatures around $478 \mathrm{~K}, 543 \mathrm{~K}, 600 \mathrm{~K}$ and above $600 \mathrm{~K}$, respectively. The kinetics of the process were evaluated using a reaction order model. Higher activation energy was recorded for the decomposition of cellulose. This was attributed to the high level of crystallinity in the materials. Some models were developed using the kinetic parameters and the data compared with the experimental data. The results of the models fit well to the experimental data. The proposed models may be a reliable means for describing the thermal decomposition of other lignocellulosic biomass samples under nitrogen atmosphere at constant heating rate, which shall be the focus of our next study.

\section{Acknowledgments}

The project was supported by the Crops for the Future (CFF) and University of Nottingham under the grant BioP1-005.

\section{Conflicts of Interest}

The authors declare no conflict of interest.

\section{References}

1. Margeot, A.; Hahn-Hagerdal, B.; Edlund, M. New improvements for lignocellulosic ethanol. Curr. Opin. Biotechnol. 2009, 20, 372-380.

2. Nigam, P.S.; Singh, A. Production of liquid biofuels from renewable resources. Prog. Energy Combust. Sci. 2011, 37, 52-68.

3. Srirangan, K.; Akawi, L.; Moo-Young, M. Towards sustainable production of clean energy carriers from biomass resources. Appl. Energy 2012, 100, 172-186.

4. Samson, R.; Mani, S.; Boddey, R. The potential of C4 perennial grasses for developing a global bioheat industry. Crit. Rev. Plant Sci. 2005, 24, 461-495.

5. Reddy, K.O.; Maheswari, C.U.; Shukla, M.; Rajulu, A.V. Chemical composition and structural characterization of Napier grass fibers. Mater. Lett. 2012, 67, 35-38.

6. Reddy, K.O.; Maheswari, C.U.; Reddy, D.J.P.; Rajulu, A.V. Thermal properties of Napier grass fibers. Mater. Lett. 2009, 63, 2390-2392.

7. Strezov, V.; Evans, T.J.; Hayman, C. Thermal conversion of elephant grass (Pennisetum Purpureum Schum) to bio-gas, bio-oil and charcoal. Bioresour. Technol. 2008, 99, 8394-8399. 
8. Lee, M.-K.; Tsai, W.-T.; Tsaic, Y.-L.; Lin, S.-H. Pyrolysis of Napier grass in an induction-heating reactor. J. Anal. Appl. Pyrolysis 2010, 88, 110-116.

9. Solid Biofuels. Determination of Moisture Content. Oven Dry Method. Total Moisture. Reference Method; BS EN 14774-1; British Standards Institution: London, UK, 2009.

10. Solid Biofuels. Determination of the Content of Volatile Matter; BS EN 15148; British Standards Institution: London, UK, 2009.

11. Solid Biofuels. Determination of Ash Content; BS EN 14775; British Standards Institution: London, UK, 2009.

12. Solid Biofuels. Determination of Calorific Value; BS EN 14918; British Standards Institution: London, UK, 2009.

13. Sluiter, A.; Hames, B.; Ruiz, R.; Scarlata, C.; Sluiter, J.; Templeton, D.; Crocker, D. Determination of structural carbohydrates and lignin in biomass. In Laboratory Analytical Procedure, NREL/TP-510-42618; National Renewable Laboratory: Golden, CO, USA, 2012.

14. Segal, L.; Creely, L.; Martin, A.E.; Conrad, C.M. An empirical method for estimating the degree of crystallinity of native cellulose using X-ray diffractometer. Text. Res. J. 1959, 29, 786-794.

15. Vassilev, S.V.; Baxter, D.; Andersen, L.K.; Vassileva, C.G. An overview of the chemical composition of biomass. Fuel 2010, 89, 913-933.

16. Lindberg, D.; Backman, R.; Chartrand, P.; Hupa, M. Towards a comprehensive thermodynamic database for ash-forming elements in biomass and waste combustion-Current situation and future developments. Fuel Process. Technol. 2013, 105, 129-141.

17. Yeboah, N.N.N.; Shearer, C.R.; Burns, S.E.; Kurtis, K.E. Characterization of biomass and high carbon content coal ash for productive reuse applications. Fuel 2014, 116, 438-447.

18. Bioenergy System Planners Handbook. Available online: http://bisyplan.bioenarea.eu/html-filesen/04-02.html (accessed on 23 April 2015).

19. DoKyung, L.; Vence, N.O.; Arvid, B.; Peter, J. Composition of herbaceous biomass feedstocks. In Sun Grant Initiative 2007; North Dakota University: Brookings, SD, USA, 2007.

20. Wada, M.; Okano, T.; Sugiyama, J. Allomorphs of native crystalline cellulose I evaluated by two equatorial d-spacings. J. Wood Sci. 2001, 47, 124-128.

21. Park, S.; Baker, J.O.; Himmel, M.E.; Parilla, P.A.; Johnson, D.K. Cellulose crystallinity index: Measurement techniques and their impact on interpreting cellulase performance. Biotechnol. Biofuels 2010, 3, 4-10.

22. Poletto, M.; Pistor, V.; Zattera, A.J. Structural characteristics and thermal properties of native cellulose. In Cellulose-Fundamental Aspects; van de Ven, T., Gdbout, L., Eds.; InTech.: Caxias do Sul, Brazil, 2013; pp. 45-68.

23. Timpano, H.; Sibout, R.; Devaux, M.-F.; Alvarado, C.; Looten, R.; Pontoire, B.; Martin, M.; Legée, F.; Cézard, L.; Lapierre, C.; et al. Brachypodium cell wall mutant with enhanced saccharification potential despite increased lignin content. Bioenerg. Res. 2014, doi:10.1007/s12155-014-9501-1.

24. Cheng, G.; Varanasi, P.; Li, C.; Liu, H.; Melnichenko, Y.B.; Simmons, B.A.; Kent, M.S.; Singh, S. Transition of cellulose crystalline structure and surface morphology of biomass as a function of ionic liquid pretreatment and its relation to enzymatic hydrolysis. Biomacromolecules 2011, 12, 933-941. 
25. Yang, H.; Yan, R.; Chen, H.; Lee, D.H.; Zheng, C. Characteristics of hemicellulose, cellulose and lignin pyrolysis. Fuel 2007, 86, 1781-1788.

26. Xu, F.; Yu, J.; Tesso, T.; Dowell, F.; Wang, D. Qualitative and quantitative analysis of lignocellulosic biomass using infrared techniques: A mini-review. Appl. Energy 2013, 104, 801-809.

27. Nazir, M.S.; Wahjoedi, B.A.; Yussof, A.W.; Abdaulla, M.A. Eco-friendly extraction and characterization of cellulose from oil palm empty fruit bunches. BioResources 2013, 8, 2161-2172.

28. Lupoi, J.S.; Singh, S.; Simmons, B.A.; Henry, R.J. Assessment of lignocellulosic biomass using analytical spectroscopy: an evolution to high-throughput techniques. Bioenergy Res. 2014, 7, 1-23.

29. Yokoi, H.; Nakase, T.; Goto, K.; Ishida, Y.; Ohtani, H.; Tsuge, S.; Sonoda, T.; Ona, T. Rapid characterization of wood extractives in wood by thermal desorption-gas chromatography in the presence of tetramethylammonium acetate. J. Anal. Appl. Pyrolysis 2003, 67, 191-200.

30. Ishida, Y.; Goto, K.; Yokoi, H.; Tsuge, S.; Ohtani, H.; Sonoda, T.; Ona, T. Direct analysis of phenolic extractives in wood by thermochemolysis-gas chromatography in the presence of tetrabutylammonium hydroxide. J. Anal. Appl. Pyrolysis 2007, 78, 200-206.

31. Mészáros, E.; Jakab, E.; Várhegyi, G. TG/MS, Py-GC/MS and THM-GC/MS study of the composition and thermal behavior of extractive components of Robinia pseudoacacia.J. Anal. Appl. Pyrolysis 2007, 79, 61-70.

32. Plis, A.; Lasek, J.; Skawinska, A.; Kopczynski, M. Thermo-chemical properties of biomass from Posidonia Oceanica. Chem. Pap. 2014, 68, 879-889.

33. Naik, S.; Goud, V.V.; Rout, P.K.; Jacobson, K.; Dalai, A.K. Characterization of Canadian biomass for alternative renewable biofuel. Renew. Energy 2010, 35, 1624-1631.

34. Nanda, S.; Mohanty, P.; Pant, K.K.; Naik, S.; Kozinski, J.A.; Dalai, A.K. Characterization of north american lignocellulosic biomass and biochars in terms of their candidacy for alternate renewable fuels. Bioenergy Res. 2013, 6, 663-677.

35. Qian, K.; Kumar, A.; Patil, K.; Bellmer, D.; Wang, D.; Yuan, W.; Raymond, L.; Huhnke, R.L. Effects of biomass feedstocks and gasification conditions on the physiochemical properties of char. Energies 2013, 6, 3972-3986.

36. Sills, D.L.; Gossett, J.M. Using FTIR to predict saccharification from enzymatic hydrolysis of alkali-pretreated biomasses. Biotechnol. Bioeng. 2012, 109, 353-362.

37. Raveendra, K.; Ganesh, A.; Khilar, K.C. Pyrolysis characteristics of biomass and biomass components. Fuel 1996, 75, 987-998.

38. Hagedorn, M.M.; Bockhorn, H.; Krebs, L.; Muller, U. A comparative kinetics study on the pyrolysis of three different wood species. J. Anal. Appl. Pyrolysis 2003, 68-69, 231-249.

39. Biwas, A.K.; Umeki, K.; Yang, W.; Blasiak, W. Change of pyrolysis characteristics and structure of wood biomass due to steam explosion pretreatment. Fuel Process. Technol. 2011, 92, 1849-1854.

40. Mohammed, I.Y.; Abakr, Y.A.; Kabir, F.; Yusuf, S. Effect of aqueous pretreatment on pyrolysis characteristics of napier grass. J. Eng. Sci. Technol. 2015, in press.

41. Khawam, A.; Flanagan, D.R. Solid-state kinetic models: Basics and mathematical fundamentals. J. Phys. Chem. B 2006, 110, 17315-17328.

42. Pasquali, C.E.L.; Herrera, H. Pyrolysis of lignin and IR analysis of residues. Thermochim. Acta 1997, 293, 39-46. 
43. Teng, H.; Wei, Y.-C. Thermogravimetric studies on the kinetics of rice hull pyrolysis and the influence of water treatment. Ind. Eng. Chem. Res. 1998, 37, 3806-3811.

44. Orfao, J.J.M.; Antunes, F.J.A.; Figueiredo, J.L. Pyrolysis kinetics of lignocellulosic materialsThree independent reactions model. Fuel 1999, 78, 349-358.

45. Brebu, M.; Vasile, C. Thermal degradation of lignin-A review. Cellul. Chem. Technol. 2010, 44, 353-363.

46. Chen, W.-H.; Kuo, P.-C. Isothermal torrefaction kinetics of hemicellulose, cellulose, lignin and xylan using thermogravimetric analysis. Energy 2011, 36, 6451-6460.

47. Braga, R.M.; Costa, T.R.; Freitas, J.C.O.; Barros, J.M.F.; Melo, D.M.A.; Melo, M.A.F. Pyrolysis kinetics of elephant grass pretreated biomasses. J. Therm. Anal. Calorim. 2014, 117, 1341-1348.

(C) 2015 by the authors; licensee MDPI, Basel, Switzerland. This article is an open access article distributed under the terms and conditions of the Creative Commons Attribution license (http://creativecommons.org/licenses/by/4.0/). 